\title{
Synthesis and Characterization of Self-Associative Perfluoroalkyl-End-Capped Polystyrene
}

\author{
Shin-ichi Yusa, ${ }^{\dagger}$ Tohei Yamamoto, Akihito Hashidzume, ${ }^{*}$ \\ and Yotaro MORISHIMA* \\ Department of Applied Chemistry, Himeji Institute of Technology, \\ 2167 Shosha, Himeji 671-2201, Japan \\ *Department of Macromolecular Science, Graduate School of Science, Osaka University, \\ Toyonaka, Osaka 560-0043, Japan
}

(Received August 27, 2001; Accepted December 27, 2001)

\begin{abstract}
Polystyrene bearing a perfluoroalkyl group at one polymer chain end was synthesized by a "living" radical polymerization of styrene in the presence of 4-perfluoro( $n$-tetradecanoylamino)-2,2,6,6-tetramethylpiperidinyl-1oxy. The "living" polymerization was evidenced by the fact that chain extension occurred upon addition of styrene to a prepolymer at an elevated temperature, i.e., the number-average molecular weight increased linearly with monomer conversion while the molecular weight distribution remained narrow independent of the conversion. The presence of the perfluoroalkyl group in the polymer was confirmed from IR and NMR $\left({ }^{1} \mathrm{H}\right.$ and $\left.{ }^{13} \mathrm{C}\right)$ spectra. A preliminary study of the associative behavior of perfluoroalkyl-end-capped polystyrene, using light scattering, spin-lattice relaxation time in ${ }^{19} \mathrm{~F}$ NMR, and fluorescence probe techniques, indicated that self-association of terminal perfluoroalkyl groups occurred in benzene at polymer concentrations higher than $c a .30 \mathrm{~g} \mathrm{~L}^{-1}$ when weight-average molecular weight is as low as 5500 .

KEY WORDS 2,2,6,6-Tetramethylpiperidinyl-1-oxy (TEMPO) / Controlled Radical Polymerization / Self-Association / Perfluoroalkyl Group /
\end{abstract}

Diblock copolymers form micelle-like aggregates as a result of the association of a less soluble block when the copolymers are dissolved in a solvent that is good for only one of the blocks. ${ }^{1-4}$ For example, amphiphilic diblock copolymers form micelles in aqueous media, hydrophobic blocks constituting a core and the hydrophilic blocks forming a corona. In analogy with amphiphilic diblock copolymers, watersoluble polymers possessing a large hydrophobic substituent at one chain end form micelle-like aggregates in water. This type of end-modified polymers has been synthesized by free-radical polymerization of hydrophilic monomers using hydrophobically modified azo initiators. For example, Winnik et al. ${ }^{5-7}$ synthesized poly( $N$-isopropylacrylamide) (PNIPAM) substituted with a dioctadecyl group at its chain end and revealed that the hydrophobe-end-modified PNIPAM formed multipolymer micelles at temperatures below its lower critical solution temperature in water. In our previous work, we synthesized poly(sodium 2-(acrylamido)-2-methylpropanesulfonate) end-capped with a cholesterol moiety and showed that the polymer underwent multipolymeric micellization in water. ${ }^{8}$

A complexity of free radical polymerization initiated by hydrophobically modified azo initiators is that chain termination occurs via recombination or disproportionation, yielding polymers with hydrophobic groups at

${ }^{\dagger}$ To whom correspondence should be addressed. both chain ends or at one chain end, respectively. Furthermore, chain transfer may result in polymers with no hydrophobic group at the polymer chain end.

Recently, a controlled radical polymerization technique with use of a nitroxide radical, such as 2,2,6,6tetramethylpiperidinyl-1-oxy (TEMPO), has been commonly employed for synthesis of polymers with welldefined end groups and controlled molecular weight with a relatively narrow molecular weight distribution $\left(M_{\mathrm{w}} / M_{\mathrm{n}}\right){ }^{9-11}$ When a polymer-substituted TEMPO derivative is used, a block copolymer can be prepared by a "living" radical mechanism. For example, polymerization of styrene in the presence of TEMPO substituted with poly(tetrahydrofuran) at the 4-position of the piperidine ring is reported to yield a diblock copolymer of polystyrene and poly(tetrahydrofuran) sequences with a well-defined structure. ${ }^{12}$ Also, polystyrene having a dendritic moiety at the polymer chain end is reported to be prepared with the same technique by employing a TEMPO derivative substituted with a dendritic moiety. ${ }^{13}$ In this work, we employed the same technique for synthesis of perfluoroalkyl-endcapped polystyrene (PStR 13 in Chart 1$)$ by using a perfluoro( $n$-tetradecanoylamino)-substituted TEMPO derivative.

Fluorocarbons exhibit various unique properties such as chemical and thermal stability, low surface energy, and low refractive index and dielectric constant. ${ }^{14,15}$ 


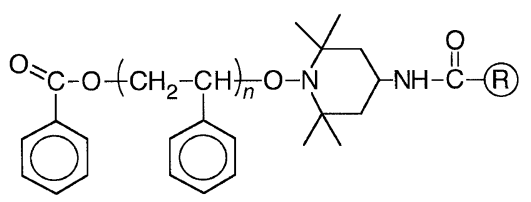

(B) $=+\left(\mathrm{CH}_{2}\right)_{13} \mathrm{H}: \mathrm{PStC} 13$

$\left.\mathrm{fCF}_{2}\right)_{13} \mathrm{~F}: \mathrm{PStR}_{\mathrm{F}} 13$

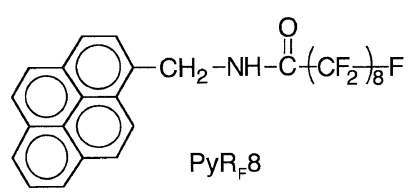

Chart 1.

They are generally poorly soluble in common organic solvents, although they are more hydrophobic than their hydrocarbon analogues. If a perfluoroalkyl group is introduced into a hydrocarbon polymer chain end, the perfluoroalkyl group is expected to be segregated from the solvent phase when the polymer is dissolved in a solvent that is not compatible with the perfluoroalkyl group, and thus micelle-like aggregates will be formed.

This paper mainly focuses on the synthetic aspect of the work, but some preliminary results on the associative properties of $\mathrm{PStR}_{\mathrm{F}} 13$ are also presented in comparison with those of polystyrene carrying an $n$ tetradecanoyl group at one polymer chain end (PStC13 in Chart 1). For the characterization of the association properties of the polymer, we employed static light scattering (SLS), ${ }^{19} \mathrm{~F}$ NMR spin-lattice relaxation time $\left(T_{1}\right)$, and fluorescence probe techniques. For a fluorescence probe having affinity to fluorocarbons, we synthesized $N$-(1-pyrenylmethyl)heptadecafluorononanoylamide $\left(\mathrm{PyR}_{\mathrm{F}} 8\right.$ in Chart 1$)$.

\section{EXPERIMENTAL}

\section{Materials}

Benzoyl peroxide (BPO) was recrystallized from methanol. Styrene was washed with an aqueous alkaline solution and distilled from calcium hydride under reduced pressure. $N, N$-Dimethylformamide (DMF) was distilled from calcium hydride under reduced pressure. Benzene and tetrahydrofuran (THF) were distilled from calcium hydride. Other reagents were used without further purification.

Synthesis of 4-n-Tetradecanoylamino-2,2,6,6-tetramethylpiperidinyl-1-oxy (TEMPOC13)

To a mixture of $4.97 \mathrm{~g}(29.0 \mathrm{mmol})$ of 4 -amino2,2,6,6-tetramethylpiperidinyl-1-oxy and $3.54 \mathrm{~g}$ $(35.0 \mathrm{mmol})$ of triethylamine in $50 \mathrm{~mL}$ of dry benzene was added dropwise $3.73 \mathrm{~g}(35.0 \mathrm{mmol})$ of $n$-tetradecanoyl chloride in $30 \mathrm{~mL}$ of dry benzene over a period of $30 \mathrm{~min}$ at room temperature. After the addition was completed, the reaction was continued for $1 \mathrm{~h}$ at room temperature and for additional $2 \mathrm{~h}$ at $70^{\circ} \mathrm{C}$. The reaction mixture was filtered to remove triethylamine hydrochloride. The filtrate was evaporated under reduced pressure to give a crude product. The crude product was purified by column chromatography with ethyl acetate and recrystallized from ethyl acetate $/ n$-hexane $(\mathrm{v} / \mathrm{v}=1 / 1)$ to give TEMPOC13 as an orange crystal: yield $86.7 \%$; mp $52-53^{\circ} \mathrm{C}$; IR $(\mathrm{KBr}$, $\left.\mathrm{cm}^{-1}\right) 3299(\mathrm{NH}), 1636(\mathrm{C}=\mathrm{O}), 1362(\mathrm{NO}) ;{ }^{1} \mathrm{H}$ NMR $\left(\mathrm{CDCl}_{3}\right.$ in the presence of phenylhydrazine) $\delta 0.88(\mathrm{t}$, $\left.3 \mathrm{H}, \mathrm{CH}_{3}\right), 1.21-1.40\left(\mathrm{~m}, 34 \mathrm{H}, \mathrm{CH}_{2}\right), 1.60(\mathrm{~m}, 2 \mathrm{H}$, $\left.\mathrm{CH}_{2}\right), 1.86\left(\mathrm{~m}, 2 \mathrm{H}, \mathrm{CH}_{2}\right), 2.11$ (t, $\left.2 \mathrm{H}, \mathrm{CH}_{2}\right), 4.19$ (m, $1 \mathrm{H}, \mathrm{CH}), 5.23(\mathrm{~m}, 1 \mathrm{H}, \mathrm{CONH})$; mass spectrum (EI) $\mathrm{m} / \mathrm{z} 381$; UV-vis (toluene) $\lambda_{\max } 468 \mathrm{~nm}(\varepsilon=11.6 \mathrm{~L}$ $\left.\mathrm{mol}^{-1} \mathrm{~cm}^{-1}\right)$.

Synthesis of 4-Perfluoro(n-tetradecanoylamino)-2,2,6,6-tetramethylpiperidinyl-1-oxy (TEMPOR $\left.{ }_{F} 13\right)$

A few drops of DMF and $25.0 \mathrm{~g}(35.0 \mathrm{mmol})$ of perfluoro( $n$-tetradecanoic acid) were dissolved in $25.0 \mathrm{~g}(0.21 \mathrm{~mol})$ of thionyl chloride. The mixture was refluxed for $1 \mathrm{~h}$ at $95^{\circ} \mathrm{C}$. Thionyl chloride was then removed under reduced pressure to give a solid of perfluoro( $n$-tetradecanoyl chloride). The product was dissolved in $50 \mathrm{~mL}$ of dry THF, and the solution was added to $100 \mathrm{~mL}$ of dry THF containing $5.0 \mathrm{~g}(29.2 \mathrm{mmol})$ of 4-amino-2,2,6,6tetramethylpiperidinyl-1-oxy and $30.3 \mathrm{~g}(0.30 \mathrm{~mol})$ of triethylamine over a period of $30 \mathrm{~min}$ at room temperature. After the addition was completed, the reaction was continued for $1 \mathrm{~h}$ at room temperature and additional $2 \mathrm{~h}$ at $70^{\circ} \mathrm{C}$. The reaction mixture was filtered to remove triethylamine hydrochloride. The filtrate was evaporated under reduced pressure to give a crude product. The crude product was recrystallized from $\mathrm{THF} / n$-hexane $(\mathrm{v} / \mathrm{v}=1 / 1)$ and $\mathrm{THF} /$ methanol $(\mathrm{v} / \mathrm{v}$ $=1 / 1)$ several times to give $\mathrm{TEMPOR}_{\mathrm{F}} 13$ as an orange crystal: yield $36.7 \%$; $\mathrm{mp} 166-169^{\circ} \mathrm{C}$; IR $\left(\mathrm{KBr}, \mathrm{cm}^{-1}\right)$ $3314(\mathrm{NH}), 1696(\mathrm{C}=\mathrm{O}), 1365(\mathrm{NO}), 1205\left(\mathrm{CF}_{3}\right), 1098$ $\left(\mathrm{CF}_{2}\right), 754\left(\mathrm{CF}_{2}\right) ;{ }^{1} \mathrm{H}$ NMR (THF- $d_{8}$ in the presence of phenylhydrazine) $\delta 1.14,1.17$ (each s, $\left.12 \mathrm{H}, \mathrm{CH}_{3}\right), 1.48$ $\left(\mathrm{m}, 2 \mathrm{H}, \mathrm{CH}_{2}\right), 1.77\left(\mathrm{~m}, 2 \mathrm{H}, \mathrm{CH}_{2}\right), 4.18(\mathrm{~m}, 1 \mathrm{H}, \mathrm{CH})$, $8.18(\mathrm{~m}, 1 \mathrm{H}, \mathrm{CONH})$; mass spectrum $(\mathrm{EI}) \mathrm{m} / \mathrm{z} 617$; UV-vis (THF) $\lambda_{\max } 456 \mathrm{~nm}\left(\varepsilon=10.9 \mathrm{~L} \mathrm{~mol}^{-1} \mathrm{~cm}^{-1}\right)$.

\section{Synthesis of N-(1-Pyrenylmethyl)heptadecafluorono-} nanoylamide $\left(P y R_{F} 8\right)$

A few drops of DMF and $10.4 \mathrm{~g}(22.4 \mathrm{mmol})$ of perfluoro( $n$-nonanoic acid) were dissolved in $25.0 \mathrm{~g}$ $(0.21 \mathrm{~mol})$ of thionyl chloride. The mixture was refluxed for $1 \mathrm{~h}$ at $95^{\circ} \mathrm{C}$. Thionyl chloride was then 
removed under reduced pressure to give a solid of perfluoro(n-nonanoyl chloride). The product was dissolved in $30 \mathrm{~mL}$ of dry THF and the solution was added to $100 \mathrm{~mL}$ of dry THF containing $5.0 \mathrm{~g}(18.7 \mathrm{mmol})$ of 1-pyrenylmethylamine hydrochloride and $18.9 \mathrm{~g}$ $(0.19 \mathrm{~mol})$ of triethylamine over a period of $30 \mathrm{~min}$ at room temperature. The reaction was continued for $1 \mathrm{~h}$ at room temperature and additional $2 \mathrm{~h}$ at $70^{\circ} \mathrm{C}$. The reaction mixture was filtered to remove triethylamine hydrochloride. The filtrate was evaporated under reduced pressure to give a crude product. The crude product was purified by column chromatography with ethyl acetate and recrystallized from ethyl acetate $/ n$ hexane $(\mathrm{v} / \mathrm{v}=1 / 1)$ to give $\mathrm{PyR}_{\mathrm{F}} 8$ as a pale yellow crystal: yield $29.2 \%$; mp $193-194^{\circ} \mathrm{C} ;{ }^{1} \mathrm{H}$ NMR (DMSO$\left.d_{6}\right) \delta 5.19\left(\mathrm{~s}, 2 \mathrm{H}, \mathrm{CH}_{2}\right), 8.04-8.43(\mathrm{~m}, 9 \mathrm{H}, \mathrm{ArH})$, 9.91 (s, 1H, CONH); UV-vis (benzene) $\lambda_{\max } 345 \mathrm{~nm}$ $\left(\varepsilon=1.19 \times 10^{5} \mathrm{~L} \mathrm{~mol}^{-1} \mathrm{~cm}^{-1}\right)$.

\section{Preparation of Prepolymers}

A representative example for the preparation of prepolymers is as follows. In a mixture of $35.0 \mathrm{~g}$ of fleshly distilled styrene and $16.5 \mathrm{~mL}$ of DMF in a glass ampul, $569 \mathrm{mg}(2.35 \mathrm{mmol})$ of BPO and $2.44 \mathrm{~g}(2.81 \mathrm{mmol})$ of TEMPOR $_{\mathrm{F}} 13$ were dissolved. The solution was outgassed on a vacuum line by six freeze-pump-thaw cycles, and then the ampul was sealed under vacuum. Polymerization was carried out for $3 \mathrm{~h}$ at $95^{\circ} \mathrm{C}$ and another $3 \mathrm{~h}$ at $125^{\circ} \mathrm{C}$. In order to terminate the polymerization, the ampul was frozen with liquid nitrogen. The polymer was recovered as a precipitate from a large excess of methanol. The product was dissolved in chloroform, reprecipitated into a large excess of methanol, and finally dried under vacuum at $60^{\circ} \mathrm{C}$ (conversion $25.9 \%$ ). Polymerization of styrene in the presence of TEMPOC13 was performed in the same manner as described above (conversion 29.5\%). These polymers were used as prepolymers for chain extension experiments.

\section{Chain Extension of Prepolymers}

A prepolymer was dissolved in styrene together with DMF as an internal standard for ${ }^{1} \mathrm{H}$ NMR in a weight ratio of prepolymer/styrene/DMF $=2 / 10 / 1$. Aliquots of the solution were charged in glass ampuls and outgassed on a vacuum line by six freeze-pump-thaw cycles and then the ampuls were sealed under vacuum. The prepolymer/styrene mixtures were heated at $125^{\circ} \mathrm{C}$ for varying periods of time followed by cooling the mixtures with liquid nitrogen. ${ }^{1} \mathrm{H}$ NMR and GPC for the reaction mixture were measured to estimate the conversion and molecular weight, respectively.

\section{Measurements}

${ }^{1} \mathrm{H}$ and ${ }^{13} \mathrm{C}$ NMR spectra were measured with a Bruker DRX500 spectrometer at a probe temperature of $27^{\circ} \mathrm{C}$. IR spectra were recorded with a JASCO FT/IR$5 \mathrm{M}$ spectrometer. UV-visible absorption spectra were measured with a Hitachi U-3000 spectrophotometer. GPC analysis was performed with a Tosoh HLC-8020 system equipped with a RI-8020 detector and a Waters Ultra Styragel Plus column using THF as an eluent. The number-average molecular weight $\left(M_{\mathrm{n}}\right)$, weightaverage molecular weight $\left(M_{\mathrm{w}}\right)$, and $M_{\mathrm{w}} / M_{\mathrm{n}}$ of sample polymers were calibrated with standard polystyrene samples of 14 different molecular weights ranging from $2.80 \times 10^{3}$ to $1.86 \times 10^{6}$.

Static light scattering (SLS) data were obtained at $25^{\circ} \mathrm{C}$ with an Otsuka Electronics Photal DLS-7000DL light scattering spectrometer. A 488-nm Ar laser was used at an output power of $75.0 \mathrm{~mW}$. The scattering angle $(\theta)$ was fixed at $90^{\circ}$. Sample solutions were filtered with a $0.2-\mu \mathrm{m}$ pore size membrane filter prior to measurement.

${ }^{19} \mathrm{~F}$ NMR spectra were measured with a JEOL LA500 spectrometer at $30^{\circ} \mathrm{C}$. A polymer sample solution in $\mathrm{C}_{6} \mathrm{D}_{6}$ containing $0.2 \%$ hexafluorobenzene as an internal standard $(-162.90 \mathrm{ppm})$ in an NMR tube was outgassed on a vacuum line by six freeze-pump-thaw cycles and then the tube was sealed under vacuum. ${ }^{19} \mathrm{~F}$ spin-lattice relaxation time $\left(T_{1}\right)$ was determined using a conventional inversion-recovery technique. ${ }^{16,17}$

Fluorescence emission spectra were recorded on a Hitachi F-4500 fluorescence spectrophotometer at room temperature. $\mathrm{PyR}_{\mathrm{F}} 8$ was used as a fluorescence probe. Sample solutions were prepared by dissolving the polymer in a benzene solution of $\operatorname{PyR}_{\mathrm{F}} 8(2.2 \times$ $\left.10^{-6} \mathrm{M}\right)$. The sample solutions were excited at $342 \mathrm{~nm}$. Excitation and emission slit widths were maintained at 5.0 and $2.5 \mathrm{~nm}$, respectively.

\section{RESULTS AND DISCUSSION}

\section{Synthesis and Molecular Characterization}

(a) Chain Extension. The essential process of the TEMPO-mediated controlled radical polymerization is the reversible trapping of the growing chain end by TEMPO yielding polymers having a TEMPO moiety at the polymer chain end. Therefore, chain extension will occur upon addition of monomers to these polymers at an elevated temperature. Figure 1 compares GPC elution curves for a sample of $\operatorname{PStR}_{\mathrm{F}} 13\left(M_{\mathrm{n}}=9600\right.$; $M_{\mathrm{w}} / M_{\mathrm{n}}=1.14$ ) before and after heating the sample in the presence of styrene at $125^{\circ} \mathrm{C}$ for $4 \mathrm{~h}$. It can be clearly seen from Figure 1 that a significant increase in the molecular weight occurs after heating the sam- 


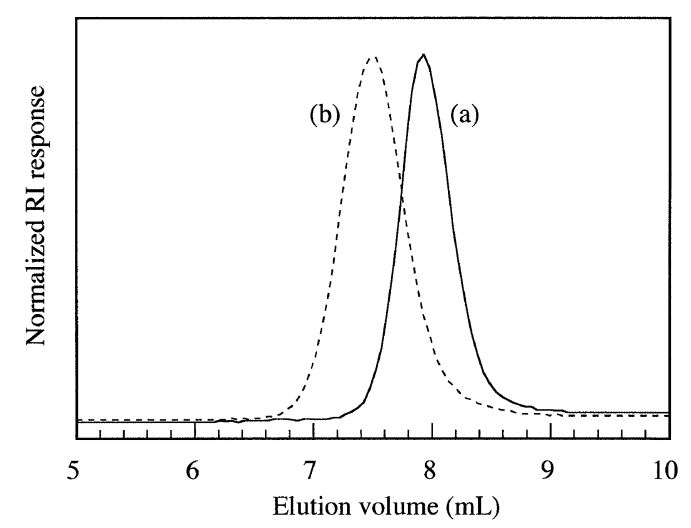

Figure 1. GPC elution curves for a sample of $\operatorname{PStR}_{\mathrm{F}} 13$ (a) before $\left(M_{\mathrm{n}}=9600 ; M_{\mathrm{w}} / M_{\mathrm{n}}=1.14\right)$ and (b) after heating with styrene at $125^{\circ} \mathrm{C}$ for $4 \mathrm{~h}\left(M_{\mathrm{n}}=19300 ; M_{\mathrm{w}} / M_{\mathrm{n}}=1.21\right)$.

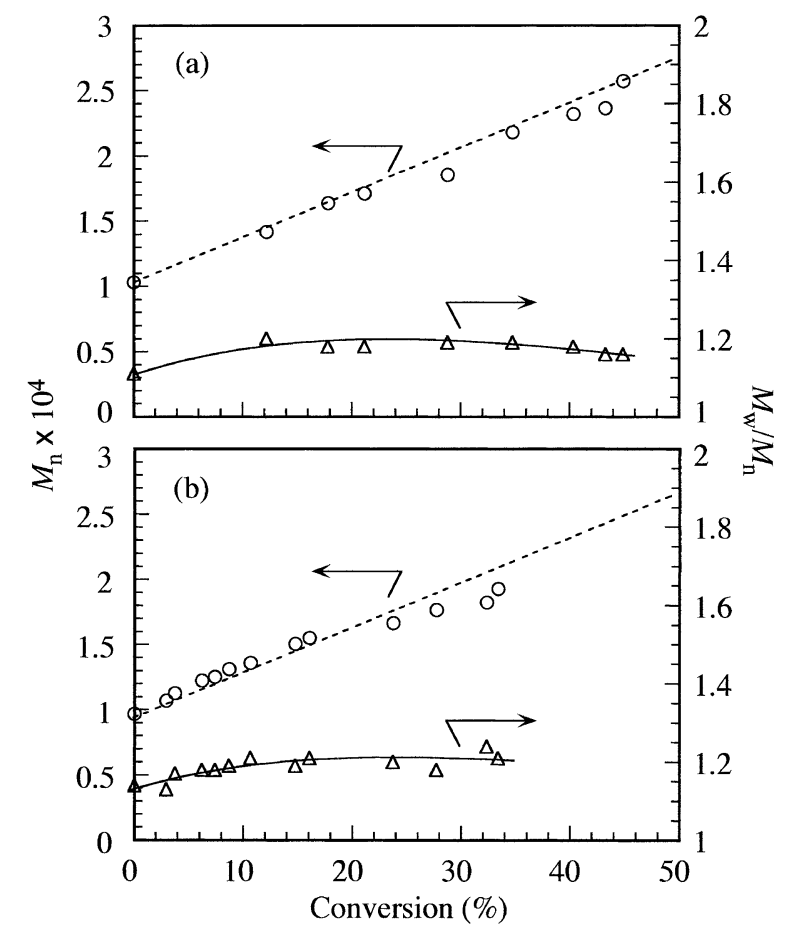

Figure 2. Dependence of $M_{\mathrm{n}}$ and $M_{\mathrm{w}} / M_{\mathrm{n}}$ on the monomer conversion in the polymerization of styrene in the presence of (a) PStC13 and (b) PStR 13 . The broken lines represent the theoretical lines.

ple with the monomer. Neither new peak nor shoulder due to polystyrene newly formed by autopolymerizaion was observed. In Figure 2, values of $M_{\mathrm{n}}$ and $M_{\mathrm{w}} / M_{\mathrm{n}}$ for $\mathrm{PStR}_{\mathrm{F}} 13$ and $\mathrm{PStC} 13$ in the chain extension polymerization are plotted as a function of the conversion of styrene determined by ${ }^{1} \mathrm{H}$ NMR. The initial values of $M_{\mathrm{n}}$ for PStC13 and PStR $\mathrm{F}_{\mathrm{F}} 13$ before chain extension ("prepolymers") are $10100\left(M_{\mathrm{w}} / M_{\mathrm{n}}=1.11\right)$ and 9600 $\left(M_{\mathrm{w}} / M_{\mathrm{n}}=1.14\right)$, respectively. $M_{\mathrm{n}}$ increased linearly with the conversion while $M_{\mathrm{w}} / M_{\mathrm{n}}$ estimated from GPC remained relatively narrow $\left(M_{\mathrm{w}} / M_{\mathrm{n}}<1.25\right)$ nearly independent of the conversion. If the polymerization proceeds via a "living" mechanism with a constant number

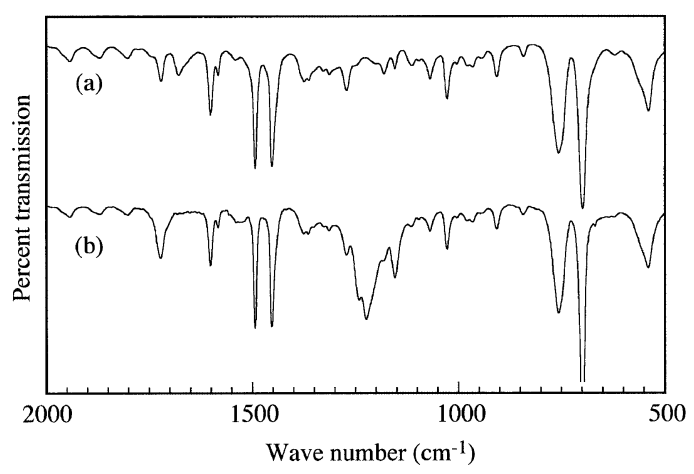

Figure 3. IR spectra of (a) PStC13 $\left(M_{\mathrm{n}}=4500 ; M_{\mathrm{w}} / M_{\mathrm{n}}=\right.$ $1.24)$ and (b) $\operatorname{PStR}_{\mathrm{F}} 13\left(M_{\mathrm{n}}=4400 ; M_{\mathrm{w}} / M_{\mathrm{n}}=1.25\right)$ measured with a KBr-pellet method.

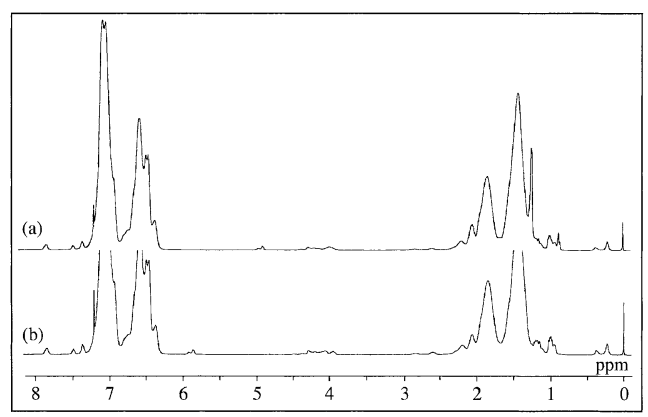

Figure 4. ${ }^{1} \mathrm{H}$ NMR spectra of (a) PStC13 $\left(M_{\mathrm{n}}=4500\right.$; $\left.M_{\mathrm{w}} / M_{\mathrm{n}}=1.24\right)$ and (b) $\operatorname{PStR}_{\mathrm{F}} 13\left(M_{\mathrm{n}}=4400 ; M_{\mathrm{w}} / M_{\mathrm{n}}=1.25\right)$ in $\mathrm{CDCl}_{3}$ at $27^{\circ} \mathrm{C}$.

of polymer chains during the polymerization, the $M_{\mathrm{n}}$ for the product polymer obtained after heating may be calculated from the equation;

$$
M_{\mathrm{n}}=\frac{[M]_{0}}{[I]_{0}} \times \frac{\text { conv }}{100} \times \mathrm{MW}+M_{\mathrm{n}}(I)
$$

where $[M]_{0}$ and $[I]_{0}$ are the initial concentrations of the monomer and the growing polymer, respectively, $\mathrm{MW}$ is the molecular weight of the monomer, conv is the conversion (\%) of the monomer, and $M_{\mathrm{n}}(\mathrm{I})$ is the numberaverage molecular weight of the initial growing polymer, i.e., $\mathrm{PStR}_{\mathrm{F}} 13$ and PStC13. ${ }^{18}$ All the experimental values of $M_{\mathrm{n}}$ agree reasonably well with $M_{\mathrm{n}}$ values calculated from eq 1. For example, when the monomer conversion is $33.4 \%$ for $\mathrm{PStR}_{\mathrm{F}} 13$ in the chain extension polymerization, the found and calculated values of $M_{\mathrm{n}}$ are 19300 and 20400, respectively. In the case of PStC13 at a conversion of $34.7 \%$, the found and calculated values are 21800 and 22300 , respectively. These results indicate that all the polymers are "living" with a TEMPO moiety at one chain end, and thus PStC13 and $\mathrm{PStR}_{\mathrm{F}} 13$ have an alkyl and perfluoroalkyl group at one end of each polymer chain, respectively.

(b) Molecular Characterization by IR and NMR Spectroscopy. A notable feature for the IR spectrum of $\mathrm{PStR}_{\mathrm{F}} 13$ is that the polymer exhibits characteristic bands at 1224 and $1154 \mathrm{~cm}^{-1}$ associated with $\delta(\mathrm{C}-\mathrm{F})$ 
in $\mathrm{CF}_{3}$ and $\mathrm{CF}_{2}$, respectively, which are absent in the IR spectrum of PStC13, indicative of the presence of the perfluoroalkyl group in $\mathrm{PStR}_{\mathrm{F}} 13$ (Figure 3).

Figure 4 shows ${ }^{1} \mathrm{H}$ NMR spectra for $\operatorname{PStC} 13\left(M_{\mathrm{n}}=\right.$ $\left.4500 ; M_{\mathrm{w}} / M_{\mathrm{n}}=1.24\right)$ and $\operatorname{PStR}_{\mathrm{F}} 13\left(M_{\mathrm{n}}=4400\right.$; $\left.M_{\mathrm{w}} / M_{\mathrm{n}}=1.25\right)$. Resonance bands were assigned on the basis of ${ }^{1} \mathrm{H}-{ }^{1} \mathrm{H}$ correlated spectroscopy (COSY), ${ }^{13} \mathrm{C}$ distortionless enhancement by polarization transfer (DEPT), and ${ }^{1} \mathrm{H}_{-}{ }^{13} \mathrm{C}$ COSY experiments. The resonance bands observed at $1.25-2.30 \mathrm{ppm}$ are attributed to the methylene and methine protons of the main chain, and those at 6.29-7.28 ppm to the phenyl protons of polystyrene. Small signals observed at 7.39, 7.52, and $7.86 \mathrm{ppm}$ were assigned to the phenyl protons at the $m-, p$-, and $o$ - positions of the benzoyl group attached to the polymer chain end, respectively. Broad resonance bands observed in the range of 3.92-4.54 ppm were assigned to the benzylic proton of the styrene unit attached to the piperidinyloxy group and the methylene protons of the styrene unit attached to the benzoate group of the polymer chain end. The four piperidinyloxy methyl resonances were assigned to signals centered at $0.23,0.38,0.99$, and $1.17 \mathrm{ppm}$, characteristic of TEMPO attached to polystyrene. ${ }^{19}$ A shielding aromatic ring-current effect of the phenyl ring of the terminal styrene monomer unit results in the splitting. ${ }^{19}$ The methyl and methylene protons of the terminal $n$ tetradecanoyl group in PStC13 were observed at 0.87 and $1.25 \mathrm{ppm}$, respectively. These resonance bands are absent in the NMR spectra of $\mathrm{PStR}_{\mathrm{F}} 13$. The resonance bands at $4.91 \mathrm{ppm}$ of PStC13 and at $5.86 \mathrm{ppm}$ of $\mathrm{PStR}_{\mathrm{F}} 13$ are attributed to the amide bond at the terminal group. Polymer tacticities may cause the amide resonance band to be split into two components. The area intensity of phenyl protons at $6.29-6.84 \mathrm{ppm}$ was compared with those of the amide groups at $4.91 \mathrm{ppm}$ for PStC13 and $5.86 \mathrm{ppm}$ for $\mathrm{PStR}_{\mathrm{F}} 13$ to estimate the ratio of styrene units to the end group. $M_{\mathrm{n}}$ thus estimated for PStC13 and $\mathrm{PStR}_{\mathrm{F}} 13$ is 4900 which is close to $M_{\mathrm{n}}$ values of 4500 and 4400 estimated by GPC for $\mathrm{PStC}_{13}$ and $\mathrm{PStR}_{\mathrm{F}} 13$, respectively. Furthermore, from the ratio of the area intensities of benzoyl protons and amide, it was confirmed that PStC13 and PStR 13 have a BPO fragment at one chain end and a TEMPO residue at the other end. The intensity of NMR signals for the TEMPO residue attached to high molecular weight polystyrene $\left(M_{\mathrm{n}}>c a\right.$. 10000) was too weak to estimate $M_{\mathrm{n}}$ by ${ }^{1} \mathrm{H}$ NMR.

Figure 5 compares ${ }^{13} \mathrm{C}$ NMR spectra for $\mathrm{PStC} 13$ $\left(M_{\mathrm{n}}=4500 ; M_{\mathrm{w}} / M_{\mathrm{n}}=1.24\right)$ and $\operatorname{PStR}_{\mathrm{F}} 13\left(M_{\mathrm{n}}=\right.$ $\left.4400 ; M_{\mathrm{w}} / M_{\mathrm{n}}=1.25\right)$ measured in $\mathrm{CDCl}_{3}$. The resonances of the terminal alkyl chain for PStC13 were observed at $14.12,22.62,25.57,29.10-29.54,31.82$, and

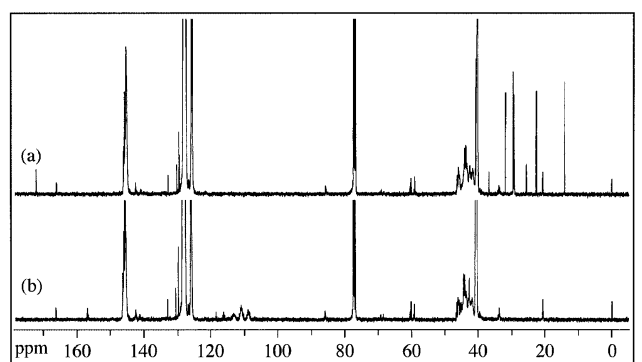

Figure 5. ${ }^{13} \mathrm{C}$ NMR spectra of (a) $\operatorname{PStC13}\left(M_{\mathrm{n}}=4500\right.$; $\left.M_{\mathrm{w}} / M_{\mathrm{n}}=1.24\right)$ and (b) $\operatorname{PStR}_{\mathrm{F}} 13\left(M_{\mathrm{n}}=4400 ; M_{\mathrm{w}} / M_{\mathrm{n}}=1.25\right)$ in $\mathrm{CDCl}_{3}$ at $27^{\circ} \mathrm{C}$.

$36.73 \mathrm{ppm}$. Resonance bands associated with the terminal perfluoroalkyl carbons for $\operatorname{PStR}_{\mathrm{F}} 13$ were observed at $108.30-118.25 \mathrm{ppm}$. The bands at $172.23 \mathrm{ppm}$ for PStC13 and 156.70 ppm for PStR $_{\mathrm{F}} 13$ are attributed to amide carbons. These observations are indicative of the presence of the TEMPO residue in the polymer.

\section{Self-Association in Benzene}

(a) Light Scattering Benzene is a good solvent for polystyrene whereas perfluoro( $n$-tetradecanoylamino)substituted TEMPO is insoluble in benzene. Thus, benzene may act as a selective solvent for the perfluoroalkyl-end-capped polystyrene, inducing the association of the terminal perfluoroalkyl groups. Winnik et al. ${ }^{5}$ reported that end-dioctadecylated PNIPAM formed spherical micelles with octadecyl groups in the core and PNIPAM chains in the corona in water at $20^{\circ} \mathrm{C}$. Similarly, the perfluoroalkyl-end-capped polystyrene may be expected to form a micelle-like aggregate with a core formed from perfluoroalkyl groups and a corona formed from polystyrene chains in benzene. Thus, we investigated the association behavior of $\mathrm{PStR}_{\mathrm{F}} 13$ in benzene employing a low molecular weight $\operatorname{PStR}_{\mathrm{F}} 13$ sample $\left(M_{\mathrm{n}}=4400, M_{\mathrm{w}}=5500\right)$ along with a low molecular weight PStC13 sample $\left(M_{\mathrm{n}}=4500\right.$, $\left.M_{\mathrm{w}}=5600\right)$ for comparison. These low molecular weight samples were prepared in a manner similar to the preparation of the "prepolymers" described above, except the polymerization was carried out for $3 \mathrm{~h}$ at $95^{\circ} \mathrm{C}$ and another $1 \mathrm{~h}$ at $125^{\circ} \mathrm{C} . M_{\mathrm{n}}$ values for the product polymers calculated on the basis of eq 1 were 4020 for PStR ${ }_{F} 13$ and 4040 for PStC13. ${ }^{18}$ These calculated values are fairly close to the $M_{\mathrm{n}}$ values estimated by GPC (4400 for PStR 13 and 4500 for PStC13). Therefore, these low molecular weight samples used for the characterization of association behavior in benzene have an alkyl and perfluoroalkyl group at each end of a polymer chain.

Figure 6 shows the dependence of the reduced Rayleigh ratio at $\theta=90^{\circ}\left(R_{90} / C_{\mathrm{p}}\right)$ on the polymer concentration $\left(C_{\mathrm{p}}\right)$ for benzene solutions of the low molec- 


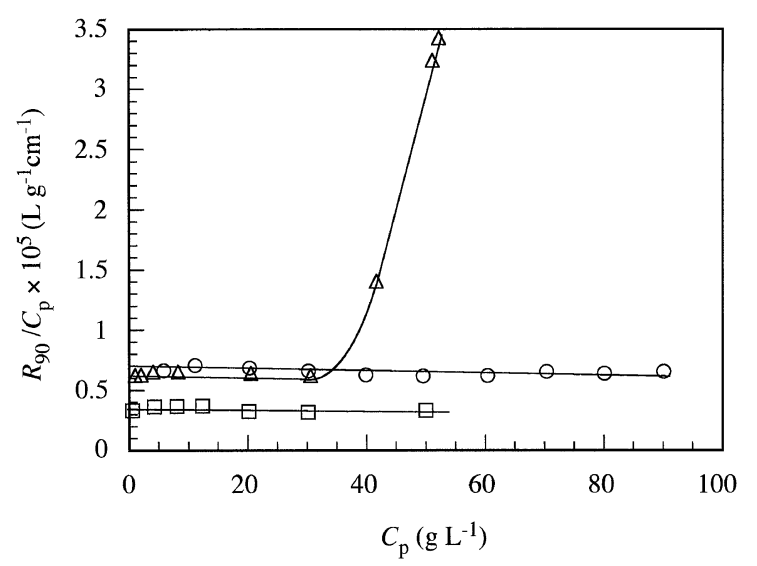

Figure 6. Reduced Rayleigh ratio $\left(R_{90} / C_{\mathrm{p}}\right)$ as a function of $C_{\mathrm{p}}$ for $(\bigcirc)$ high molecular weight $\operatorname{PStR}_{\mathrm{F}} 13\left(M_{\mathrm{n}}=9600 ; M_{\mathrm{w}}=\right.$ $11000),(\triangle)$ low molecular weight $\operatorname{PStR}_{\mathrm{F}} 13\left(M_{\mathrm{n}}=4400 ; M_{\mathrm{w}}=\right.$ $5500)$, and () PStC13 $\left(M_{\mathrm{n}}=4500 ; M_{\mathrm{w}}=5600\right)$ in benzene at $25^{\circ} \mathrm{C}$

ular weight $\mathrm{PStR}_{\mathrm{F}} 13$ and $\mathrm{PStC} 13$ together with data for a higher molecular weight $\operatorname{PStR}_{\mathrm{F}} 13\left(M_{\mathrm{n}}=9600\right.$, $\left.M_{\mathrm{w}}=11000\right)$ for comparison. This high molecular $\mathrm{PStR}_{\mathrm{F}} 13$ is the same polymer sample used as "prepolymer" for the chain extension experiment described above. It is known that $R_{90} / C_{\mathrm{p}}$ is proportionally related to $M_{\mathrm{w}}$. In the case of PStC13 and the high molecular weight $\mathrm{PStR}_{\mathrm{F}} 13\left(M_{\mathrm{w}}=11000\right), R_{90} / C_{\mathrm{p}}$ is independent of $C_{\mathrm{p}}$, indicating that the weight-average molar masses of PStC13 and the high molecular weight $\mathrm{PStR}_{\mathrm{F}} 13$ in benzene are constant over the range of $C_{\mathrm{p}}$ examined. In contrast, $R_{90} / C_{\mathrm{p}}$ for the low molecular weight $\operatorname{PStR}_{\mathrm{F}} 13\left(M_{\mathrm{W}}=5500\right)$ increases sharply with increasing $C_{\mathrm{p}}$ at $C_{\mathrm{p}}>30 \mathrm{~g} \mathrm{~L}^{-1}$ although it is nearly constant at $C_{\mathrm{p}} \leq 30 \mathrm{~g} \mathrm{~L}^{-1}$. This observation indicates that the low molecular weight $\mathrm{PStR}_{\mathrm{F}} 13$ forms aggregates at $C_{\mathrm{p}}>30 \mathrm{~g} \mathrm{~L}^{-1}$ in benzene. The $R_{90} / C_{\mathrm{p}}$ value for the aggregate at $C_{\mathrm{p}}=50 \mathrm{~g} \mathrm{~L}^{-1}$ was about 5 times larger than that for a single polymer chain of the low molecular weight $\mathrm{PStR}_{\mathrm{F}} 13$ at $C_{\mathrm{p}} \leq 30 \mathrm{~g} \mathrm{~L}^{-1}$. This observation implies that the number of polymer chains $\left(N_{\mathrm{agg}}\right)$ belonging to one aggregate at $C_{\mathrm{p}}=50 \mathrm{~g} \mathrm{~L}^{-1}$ for the low molecular weight $\mathrm{PStR}_{\mathrm{F}} 13$ is about 5 on the basis of the fact that $R_{90} / C_{\mathrm{p}}$ is proportionally related to the weightaverage molar mass.

Unfortunately, we were unable to determine hydrodynamic radii for $\mathrm{PStC} 13$ and $\mathrm{PStR}_{\mathrm{F}} 13$ by quasielastic light scattering measurements because the scattering intensity of the low molecular weight polystyrene samples was not strong enough to give a meaningful correlation function. Also, we were unable to obtain the radius of gyration $\left(R_{\mathrm{g}}\right)$ of the polymer aggregate by SLS probably because $R_{\mathrm{g}}$ for the aggregate is smaller than the lower limit of detection on our light scattering instrument. Yamamoto et al. ${ }^{20}$ reported that $R_{\mathrm{g}}$ of polystyrene in benzene at $25^{\circ} \mathrm{C}$ is calculated from

$$
R_{\mathrm{g}}=0.0139 \times M_{\mathrm{w}}{ }^{0.585}
$$

Assuming $M_{\mathrm{W}}=28000$ for the polymer aggregate $\left(N_{\mathrm{agg}}=5\right)$ formed from $\operatorname{PStR}_{\mathrm{F}} 13\left(M_{\mathrm{w}}=5500\right), R_{\mathrm{g}}$ can be calculated to be $5.6 \mathrm{~nm}$ from eq 2 .

Polystyrene and perfluoro( $n$-tetradecanoylamino)substituted TEMPO are both soluble in THF, and thus THF is expected to act as a non-selective solvent. In fact, it was confirmed that no such an increase in $R_{90} / C_{\mathrm{p}}$ was observed for $\mathrm{PStR}_{\mathrm{F}} 13$ in THF regardless of its molecular weight in the $C_{\mathrm{p}}$ range examined $(<90 \mathrm{~g}$ $\mathrm{L}^{-1}$ ). These observations indicate that the terminal perfluoroalkyl groups aggregate in benzene only if the $M_{\mathrm{w}}$ of the polymer is as low as 5500. In benzene solutions, low molecular weight polystyrene would exist as a worm-like chain, whereas the polymer would adopt a random coil conformation as the molecular weight increases. It is expected that a worm-like chain is more favorable than a random coil for the association of the terminal perfluoroalkyl groups because an excluded volume effect is less important for the worm-like chain. Moreover, the balance of the affinity of the main chain and the terminal group to the solvent (i.e., the relative size of the polymer main chain and the terminal group) should also be an important factor to control the association of the terminal perfluoroalkyl groups. Therefore, the association of the terminal perfluoroalkyl groups should become unfavorable as the molecular weight of the polymer increases.

(b) ${ }^{19} \mathrm{~F}$ NMR Relaxation Time. ${ }^{19} \mathrm{~F}$ NMR relaxation techniques would provide qualitative information about local motions of perfluoroalkyl groups. ${ }^{21-24} \mathrm{Ad}-$ vantages of using ${ }^{19} \mathrm{~F}$ NMR include its high sensitivity due to the $100 \%$ natural abundance of ${ }^{19} \mathrm{~F} \cdot{ }^{21-24}$ We performed ${ }^{19} \mathrm{~F}$ NMR relaxation time measurements in $\mathrm{C}_{6} \mathrm{D}_{6}$ to obtain information about changes in dynamic motions of the perfluoroalkyl group in $\mathrm{PStR}_{\mathrm{F}} 13$ upon self-association. The spin-lattice relaxation occurs most effectively through molecular motions whose frequency is comparable to the NMR frequency. Therefore, the spin-lattice relaxation time $\left(T_{1}\right)$ decreases as the molecular motion decreases. ${ }^{25}$ The perfluoroalkyl group of $\mathrm{PStR}_{\mathrm{F}} 13$ in $\mathrm{C}_{6} \mathrm{D}_{6}$ showed sharp and wellresolved ${ }^{19} \mathrm{~F}$ NMR signals (an insert in Figure 7). For the calculation of $T_{1}$, we chose a resonance band centered at $-122.75 \mathrm{ppm}$ that is associated with the $-\mathrm{CF}_{2-}$ group, because this signal is not overlapped with other signals. In Figure 7, $T_{1}$ is plotted as a function of $C_{\mathrm{p}}$. At $C_{\mathrm{p}} \leq 30 \mathrm{~g} \mathrm{~L}^{-1}$, the $T_{1}$ values are constant at $615 \mathrm{~ms}$. However, $T_{1}$ decreases with increasing $C_{\mathrm{p}}$ at $C_{\mathrm{p}}>30 \mathrm{~g} \mathrm{~L}^{-1}$, indicating that motions of the perfluoroalkyl group in $\mathrm{PStR}_{\mathrm{F}} 13$ become more restricted with 


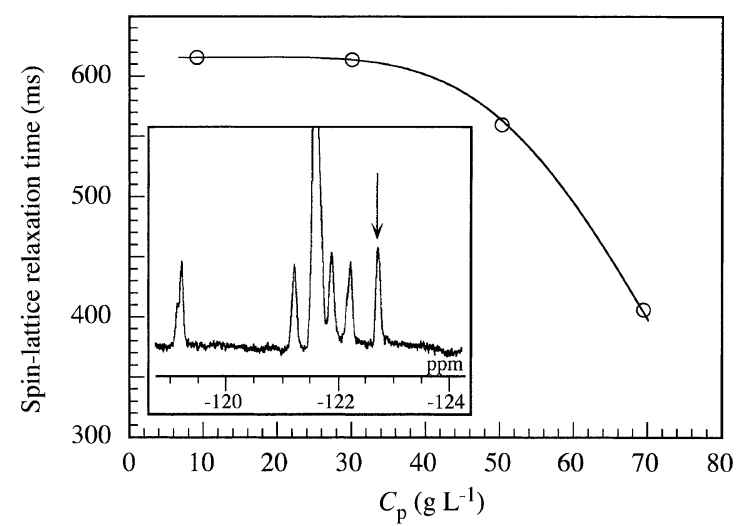

Figure 7. ${ }^{19} \mathrm{~F}$ NMR spin-lattice relaxation times $\left(T_{1}\right)$ for the perfluoroalkyl group in $\operatorname{PStR}_{\mathrm{F}} 13\left(M_{\mathrm{n}}=4400 ; M_{\mathrm{w}} / M_{\mathrm{n}}=1.25\right)$ at $-122.75 \mathrm{ppm}$ as a function of the polymer concentration in $\mathrm{C}_{6} \mathrm{D}_{6}$. $A{ }^{19} \mathrm{~F}$ NMR spectrum for $\mathrm{PStR}_{\mathrm{F}} 13$ is presented in the insert.

increasing $C_{\mathrm{p}}$ in $\mathrm{C}_{6} \mathrm{D}_{6}$ at $C_{\mathrm{p}}>30 \mathrm{~g} \mathrm{~L}^{-1}$. These observations suggest the formation of microdomains by the association of the terminal perfluoroalkyl groups in $\mathrm{C}_{6} \mathrm{D}_{6}$ at $C_{\mathrm{p}}>30 \mathrm{~g} \mathrm{~L}^{-1}$.

(c) Fluorescence. The ratio of the intensity of the first and third vibronic bands $\left(I_{3} / I_{1}\right)$ in pyrene fluorescence spectra can be used as a measure of local polarity about pyrene probes, $I_{3} / I_{1}$ being larger in less polar microenvironments. ${ }^{26}$ Thus, pyrene fluorescence is often used for studying the self-association behavior of polymers in systems where pyrene probes are selectively solubilized in the polymer phase that is less polar than the solvent phase. ${ }^{27-29}$ In the present study, however, pyrene is not a suitable probe for studying the self-association behavior of perfluoroalkyl groups because of poor affinity of pyrene to fluorocarbon moieties. $^{30}$ To improve its affinity for perfluoroalkyl microdomains, we employed a derivative of pyrene substituted with a perfluoroalkyl moiety $\left(\mathrm{PyR}_{\mathrm{F}} 8\right.$ in Chart 1). This perfluoroalkyl-substituted pyrene exhibits steadystate fluorescence spectra with a common feature of vibronic bands of pyrene molecules, and the relative intensities of the vibronic bands depend on solvent. The values of $I_{3} / I_{1}$ for $\mathrm{PyR}_{\mathrm{F}} 8$ in benzene and in perfluorohexane were found to be 0.68 and 0.91 , respectively (Figure 8a). It is generally accepted that perfluoroalkyl groups are more hydrophobic than their hydrocarbon analogues, ${ }^{31}$ and thus these values of $I_{3} / I_{1}$ reflect microenvironmental polarities about the probe.

In Figure $8 \mathrm{~b}, I_{3} / I_{1}$ ratios for $\mathrm{PyR}_{\mathrm{F}} 8$ in the presence of $\mathrm{PStC}_{13}$ and $\mathrm{PStR}_{\mathrm{F}} 13$ in benzene are plotted as a function of $C_{\mathrm{p}}$. The $I_{3} / I_{1}$ ratios in the presence of PStC13 are almost constant near 0.68 at $C_{\mathrm{p}}<20 \mathrm{~g} \mathrm{~L}^{-1}$, although the ratio increases slightly with increasing $C_{\mathrm{p}}$ at higher polymer concentrations. Therefore, $\mathrm{PyR}_{\mathrm{F}} 8$ experiences the polarity of the solvent phase in the presence of PStC13. In the case of $\mathrm{PStR}_{\mathrm{F}} 13$, on the other
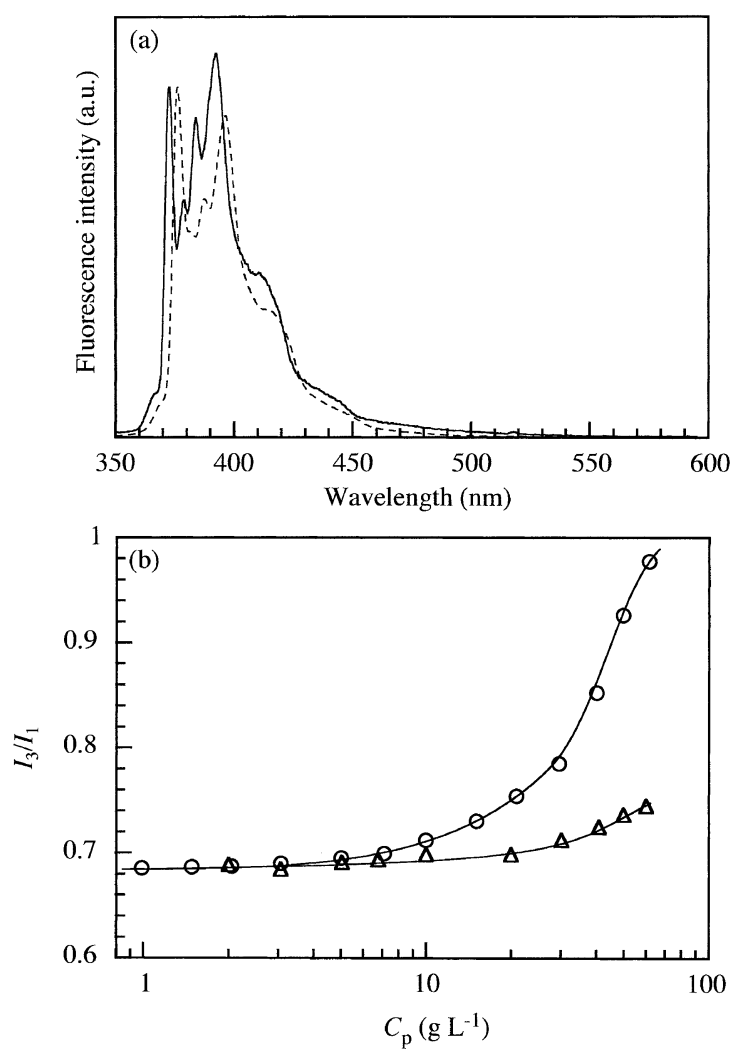

Figure 8. (a) Fluorescence spectra of $\mathrm{PyR}_{\mathrm{F}} 8$ normalized at the first vibronic (0-0) bands in benzene (---) and perfluorohexane () observed at a $\mathrm{PyR}_{\mathrm{F}} 8$ concentration of $2.2 \times 10^{-6} \mathrm{M}$ with excitation at $342 \mathrm{~nm}$. (b) Plots of $I_{3} / I_{1}$ in $\mathrm{PyR}_{\mathrm{F}} 8$ fluorescence spectra as a function of the polymer concentration for $(\triangle) \operatorname{PStC13}\left(M_{\mathrm{n}}=4500\right.$; $\left.M_{\mathrm{w}} / M_{\mathrm{n}}=1.24\right)$ and $(\bigcirc) \operatorname{PStR}_{\mathrm{F}} 13\left(M_{\mathrm{n}}=4400 ; M_{\mathrm{w}} / M_{\mathrm{n}}=1.25\right)$ in benzene.

hand, $I_{3} / I_{1}$ ratios are practically constant at 0.68 in a lower $C_{\mathrm{p}}$ region, but the ratio starts to increase near $C_{\mathrm{p}}=5 \mathrm{~g} \mathrm{~L}^{-1}$ with increasing $C_{\mathrm{p}}$. A gradual increase in $I_{3} / I_{1}$ continues up to a polymer concentration near $30 \mathrm{~g} \mathrm{~L}^{-1}$, and the ratio increases more significantly at $C_{\mathrm{p}}>30 \mathrm{~g} \mathrm{~L}^{-1}$. These observations suggest that the association of the terminal perfluoroalkyl groups starts to occur at a polymer concentration as low as $5 \mathrm{~g} \mathrm{~L}^{-1}$ but it significantly increases at $C_{\mathrm{p}}>30 \mathrm{~g} \mathrm{~L}^{-1}$. This polymer concentration at which a significant increase in the association was observed agree with the results of $R_{90} / C_{\mathrm{p}}$ and $T_{1}$. The gradual increase in $I_{3} / I_{1}$ in the lower $C_{\mathrm{p}}$ region may reflect an increment of the solubilization of $\mathrm{PyR}_{\mathrm{F}} 8$ in smaller aggregates of the terminal perfluoroalkyl groups. The affinity of $\mathrm{PyR}_{\mathrm{F}} 8$ to the perfluoroalkyl group may be high enough to be able to detect the formation of perfluoroalkyl aggregates in the process where their size grows gradually with increasing $C_{\mathrm{p}}$. 


\section{CONCLUSIONS}

Polystyrene bearing a perfluoro( $n$-tetradecanoyl) group at one chain end $\left(\mathrm{PStR}_{\mathrm{F}} 13\right)$ was prepared by controlled radical polymerization of styrene using perfluoro( $n$-tetradecanoylamino)-substituted TEMPO. The polymerization proceeded in accordance with a "living" mechanism that was confirmed by the fact that $M_{\mathrm{n}}$ increased linearly with the conversion of the monomer. The introduction of the perfluoroalkyl group into polystyrene was confirmed from IR, NMR $\left({ }^{1} \mathrm{H}\right.$ and ${ }^{13} \mathrm{C}$ ) measurements. The self-association behavior of $\mathrm{PStR}_{\mathrm{F}} 13$ in benzene was preliminarily investigated by SLS, ${ }^{19} \mathrm{~F}$ NMR relaxation, and fluorescence probe techniques. When $M_{\mathrm{W}}$ was lower than $5500, \mathrm{PStR}_{\mathrm{F}} 13$ formed polymer aggregates at $C_{\mathrm{p}}>c a .30 \mathrm{~g} \mathrm{~L}^{-1}$ in benzene that is a good solvent for polystyrene but is poor solvent for the perfluoroalkyl group. No such aggregation occurs in THF that is a good solvent for both polystyrene and the perfluoroalkyl group. When $M_{\mathrm{w}}$ was higher than $11000, \mathrm{PStR}_{\mathrm{F}} 13$ showed no associative behavior in benzene, indicating that the longer polymer chains prevent the association of the terminal perfluoroalkyl groups.

These preliminary results on the associative properties of the perfluoroalkyl-end-capped polystyrene prompted us to undertake a comprehensive study with polymers of a series of molecular weights as a function of solvent quality and temperature. The work along this line is now underway in our group.

\section{REFERENCES}

1. A. Qin, M. Tian, C. Ramireddy, S. E. Webber, and P. Munk, Macromolecules, 27, 3276 (1994).

2. A. L. Borovinskii and A. R. Khokhlov, Macromolecules, 31, 1180 (1998)

3. I. Astafieva, X. F. Zhong, and A. Eisenberg, Macromolecules, 26, 7339 (1993).

4. A. Halperin, Macromolecules, 20, 2943 (1987).

5. F. M. Winnik, A. R. Davidson, and G. K. Hamer, Macromolecules, 25, 1876 (1992).

6. T. C. Barros, F. M. Winnik, and C. Bohne, Langmuir, 13, 6089
(1997).

7. A. Yamazaki, J. M. Song, F. M. Winnik, and J. L. Brash, Macromolecules, 31, 109 (1998).

8. S. Yusa, M. Kamachi, and Y. Morishima, Macromolecules, 33, 1224 (2000).

9. M. K. Georges, R. P. N. Veregin, P. M. Kazmaier, and G. K. Hamer, Macromolecules, 26, 2987 (1993).

10. E. Yoshida and S. Tanimoto, Macromolecules, 30, 4018 (1997).

11. T. Fukuda, T. Terauchi, A. Goto, K. Ohno, Y. Tsujii, T. Miyamoto, S. Kobatake, and B. Yamada, Macromolecules, 29, 6393 (1996).

12. E. Yoshida and A. Sugita, Macromolecules, 29, 6422 (1996).

13. K. Matyjaszewski, T. Shigemoto, J. M. J. Fréchet, and M. Leduc, Macromolecules, 29, 4167 (1996).

14. J. F. Liebman and A. Greenberg, in " Molecular Structrre and Energetics: Fluorine-Containing Molecules", John Wiley \& Sons, Inc., New York, N.Y., 1988, vol. 8.

15. L. A. Wall, in "Fluoropolymer", John Wiley \& Sons, Inc., New York, N.Y., 1972, vol. 25.

16. R. L. Vold, J. S. Waugh, M. P. Klein, and D. E. Phelps, J. Chem. Phys., 48, 3831 (1968).

17. W. E. Hull and B. D. Sykes, J. Chem. Phys., 63, 867 (1975).

18. E. Yoshida and Y. Okada, J. Polym. Sci., Polym. Chem. Ed., 34, 3631 (1996).

19. M. K. Georges, R. P. N. Vergin, P. M. Kazmaier, and G. K. Hamer, Trends Polym. Sci., 2, 66 (1994).

20. A. Yamamoto, M. Fujii, G. Tanaka, and H. Yamakawa, Polym. J., 2, 799 (1971).

21. W. E. Hull and B. D. Sykes, J. Chem. Phys., 63, 867 (1975).

22. J. Ulmus and B. Lindman, J. Phys. Chem., 85, 4131 (1981).

23. T. Nowak and P. J. Maurer, Biochemistry, 20, 6901 (1981).

24. B. J. Marwedel, D. J. Kosman, R. D. Bereman, and R. J. Kurland, J. Am. Chem. Soc., 103, 2842 (1981).

25. G. E. Pake, in "Solid State Physics", F. Seitz and D. Turnbull, Ed., Academic Press, Inc., New York, N.Y., 1965.

26. K. Kalyanasundaram and J. K. Thomas, J. Am. Chem. Soc., 99, 2039 (1977).

27. H. Faes, F. C. D. Schryver, A. Sein, K. Bijma, J. Kevelam, and J. B. F. N. Engberts, Macromolecules, 29, 3875 (1996).

28. K. Procházka, T. J. Martin, P. Munk, and S. E. Webber, Macromolecules, 29, 6518 (1996).

29. E. Alami, M. Almgren, W. Brown, and J. François, Macromolecules, 29, 2229 (1996).

30. M. Li, M. Jiang, Y.-X. Zhang, and Q. Fang, Macromolecules, 30, 470 (1997).

31. D. Y. Myers, Jr., in "Surfactant Science and Technology", John Wiley \& Sons, Inc., New York, N.Y., 1988. 